\title{
Apnoea and hypopnoea scoring for people with spinal cord injury: new thresholds for sleep disordered breathing diagnosis and severity classification
}

\author{
Rachel Schembri (1) ${ }^{1,2}$ Marnie Graco $\mathbb{1}^{1,2} \cdot$ Jo Spong $^{2,3} \cdot$ Warren R. Ruehland ${ }^{2} \cdot$ Julie Tolson $^{2} \cdot$ Peter D. Rochford ${ }^{2} \cdot$ \\ Brett Duce $^{4,5} \cdot$ Bronwyn Stevens $^{2} \cdot$ David J. Berlowitz $\mathbb{i}^{1,2}$
}

Received: 10 May 2018 / Revised: 22 November 2018 / Accepted: 27 November 2018 / Published online: 9 January 2019

(c) International Spinal Cord Society 2019

\begin{abstract}
Study design Descriptive study.

Objectives To determine the effect of respiratory event rule-set changes on the apnoea hypopnoea index, and diagnostic and severity thresholds in people with acute and chronic spinal cord injury.

Setting Eleven acute spinal cord injury inpatient hospitals across Australia, New Zealand, Canada and England; community dwelling chronic spinal cord injury patients in their own homes.

Methods Polysomnography of people with acute $(n=24)$ and chronic $(n=78)$ tetraplegia were reanalysed from 1999 American Academy of Sleep Medicine (AASM) respiratory scoring, to 2007 AASM 'alternative' and 2012 AASM respectively. Equivalent cut points for published 1999 AASM sleep disordered breathing severity ranges were calculated using receiver operator curves, and results presented alongside analyses from the able-bodied.

Results In people with tetraplegia, shift from 1999 AASM to 2007 AASM 'alternative' resulted in a $22 \%$ lower apnoea hypopnoea index, and to 2012 AASM a 17\% lower index. In people with tetraplegia, equivalent cut-points for 1999 AASM severities of 5,15 and 30 were calculated at 2.4, 8.1 and 16.3 for 2007 AASM 'alternative' and 3.2, 10.0 and 21.2 for 2012 AASM.

Conclusion Interpreting research, prevalence and clinical polysomnography results conducted over different periods requires knowledge of the relationship between different rule-sets, and appropriate thresholds for diagnosis of disease.

Sponsorship This project was proudly supported by the Traffic Accident Commission (Program grant) and the National Health and Medical Research Council (PhD stipend 616605).
\end{abstract}

Supplementary information The online version of this article (https:// doi.org/10.1038/s41393-018-0229-1) contains supplementary material, which is available to authorized users.

Rachel Schembri

rachel.schembri@austin.org.au

1 University of Melbourne, Department of Medicine, Melbourne, Australia

2 Institute for Breathing and Sleep, Austin Health, Melbourne, Australia

3 College of Science, Health and Engineering, La Trobe Rural Health School, La Trobe University, Bendigo, Australia

4 Sleep Disorders Centre, Department of Respiratory and Sleep Medicine, Princess Alexandra Hospital, Brisbane, Australia

5 Institute for Health and Biomedical Innovation, Queensland University of Technology, Brisbane, Australia

\section{Introduction}

Sleep disordered breathing (SDB) is a highly prevalent secondary complication following spinal cord injury (SCI). As many as $91 \%$ of people with complete tetraplegia have SDB, with or without clinical signs [1, 2]. Tetraplegia substantially reduces health, but SDB confers additional, statistically and clinically significant impairments to health status [3] and neuropsychological function [4, 5]. As such, appropriate diagnosis and treatment of SDB following SCI is of high importance.

Sleep disordered breathing diagnosis and severity is typically quantified by the apnoea hypopnoea index (AHI), a measure of the number of apnoeas (cessations of breathing) and hypopnoeas (reductions in breathing) per hour of sleep. Although the prevalence of SDB in people with SCI has been widely reported as elevated in the literature, 
differing patient characteristics, study methodology, and importantly, changes over time in the rules defining respiratory events (apnoeas and hypopnoeas) are important challenges in pooling [6] and ideally meta-analysing the population prevalence data. In 1968 Rechtschaffen and Kales $(R \& K)$ produced the first standardised methodology for analysing sleep from polysomnography (PSG) [7], and in 1999 the American Academy of Sleep Medicine (AASM) produced a consensus set of rules for defining respiratory events during sleep $\left(\mathrm{AASM}_{1999}\right)$ and recommendations for SDB diagnosis $(\mathrm{AHI} \geq 5)$ and severity thresholds (mild SDB AHI $\geq 5-15$; moderate SDB AHI > 15-30; severe SDB AHI > 30) [8]. In 2007 the AASM released an updated, integrated manual for both sleep staging and respiratory scoring $\left(\mathrm{AASM}_{2007}\right)$ [9], with a further revision in 2012 $\left(\mathrm{AASM}_{2012}\right)$ [10]. Each rule set revision has changed respiratory event scoring criteria, particularly for hypopnoeas [10], with $\mathrm{AASM}_{2007}$ having two hypopnoea definitions, recommended (REC) and alternative (ALT). The change from $\mathrm{AASM}_{1999}$ to $\mathrm{AASM}_{2007}$ was essentially one of stricter criteria, resulting in lower AHIs for any given severity of SDB, while the change from $\mathrm{AASM}_{2007}$ to AASM $_{2012}$ was more inclusive and resulted in higher AHIs, although not as high as $\mathrm{AASM}_{1999}$ [11]. These changes have necessitated altered clinical interpretation of AHI values and diagnostic and severity thresholds, which have not been specifically updated to reflect the changed respiratory event criteria. As Chiodo et al observed [6], heterogeneity in testing technologies and the aforementioned rule-set changes have limited pooling of previous studies in SCI. We speculate that rule-set changes have undermined our ability to specifically define the burden of SDB in SCI and thus a consequent failure to adequately diagnose and treat the disease. This paper aims to address this issue by quantifying the impact of rule-set changes on the AHI, and thus providing a framework for interpretation over time.

Research conducted with full PSG, directly comparing AASM rule sets, have analysed change in AHI in sleep laboratory samples [11-13], lean (body mass index (BMI) in the normal range) obstructive sleep apnoea (OSA) patients [14], chronic SCI patients [2], and community samples $[15,16]$. Other research has also compared AHIs with respiratory criteria which did not directly align with any AASM rule set [17, 18], with only respiration measured (not sleep) [17, 19], and within one rule-set only (the two $\mathrm{AASM}_{2007}$ criteria) [20]. The Australasian Sleep Technologist and Australasian Sleep Associations recommend [21] using the 'alternative' $\mathrm{AASM}_{2007}$ hypopnoea definition $\left(\mathrm{AASM}_{2007-\mathrm{ALT}}\right.$ rather than $\left.\mathrm{AASM}_{2007-\mathrm{REC}}\right)$ and as such, the current study aimed to generate new AHI cut-points for diagnosis and severity of SDB in SCI using three AASM rule-sets commonly reported in, and recommended for use by, the literature. Of note, cut-points for SDB severity (mild, moderate and severe) were defined in the 1999 AASM document [8] and as such comparisons of severity should be made relative to this rule-set. Specifically, comparisons of the $\mathrm{AASM}_{1999} \mathrm{AHI}\left(\mathrm{AHI}_{1999}\right)$ to the $\mathrm{AASM}_{2007}$ 'alternative' AHI (AHI 2007 -ALT), and the $\mathrm{AHI}_{1999}$ to the $\mathrm{AASM}_{2012}$ AHI (AHI 2012$)$, in two research samples that sought to diagnose SDB in people with tetraplegia. Further, the current study provides a framework for consideration of the changes in respiratory event scoring, and the effect of rule-set modifications on comparisons between SCI and able-bodied samples.

\section{Methods}

Two previously collected datasets from two separate studies in people with tetraplegia were re-analysed with a different rule set than used in the original analyses. The first study was a randomised controlled trial of continuous positive airway pressure for people with acute tetraplegia (inclusion criteria was injury duration $<1$ year) [22]. The second study was a population cohort study [1] conducted to develop and validate a sleep apnoea screening model for people with chronic tetraplegia (inclusion criteria was injury duration $>1$ year) [23]. Both projects employed portable, unattended, full PSG with a Type 2 ambulatory device (Somte; Compumedics, Victoria, Australia) performed in participant's acute or rehabilitation hospital beds or homes. The signals collected with the Type 2 (home) device are of the same type and employ the same technologies, filter settings, etc. as in-laboratory studies. Both research projects received ethics approval from the Austin Health Human Research Ethics Committee.

Analysis 1 examined a convenience sample of 24 PSGs, drawn from 88 PSGs from the first study, and compared the $\mathrm{AHI}_{1999}$ and $\mathrm{AHI}_{2007-\mathrm{ALT}}$. This sample of 24 PSGs was split into terciles according to AHI with eight PSGs randomly selected from each tercile. Analysis 2 examined 78 PSGs from the second study in which the $\mathrm{AHI}_{1999}$ was compared to $\mathrm{AHI}_{2012}$. For both analyses montages and filters were set as per each scoring criteria manual, and apnoeas and hypopnoeas were scored from nasal flow and respiratory inductance plethysmography. Sleep and respiratory events were manually staged and scored according to each rule set, and summary indices generated with Profusion 3 software (Compumedics, Victoria, Australia). The AHIs were compared using paired t-tests, rate of misclassification was tabulated, and equivalent AHI severity cut-offs (for AASM $_{1999}$ cut-points of 5, 15 and 30) calculated using receiver operating characteristic (ROC) curves and accompanying sensitivity and specificity values. The results of Analysis 1 and 2 are presented alongside data from similar 
'rule-set comparison' studies conducted in the able-bodied $[11,12]$. Previously published data are presented for Ruehland, Rochford [12], and raw de-identified data was obtained from Duce, Milosavljevic [11] to calculate AHI severity cut-offs via ROC curves, sensitivity and specificity.

\section{Analysis 1}

The Australasian Sleep Technologist and Australasian Sleep Associations commentary recommendations [21] on the $\mathrm{AASM}_{2007}$ criteria were applied, and the 'alternative' hypopnoea definition used $\left(\mathrm{AASM}_{2007-\mathrm{ALT}}\right.$ rather than $\left.\mathrm{AASM}_{2007-\mathrm{REC}}\right)$. Prior to any analyses, three experienced (>10 years) sleep scientists undertook a quality control and technique alignment exercise to optimise scoring consistency.

Each PSG was de-identified, previous analyses deleted and all PSGs analysed with one rule-set at a time (a 'block' of PSGs). The order of PSG blocks was randomly allocated for each scientist. The order of the PSGs within each block was also randomised each time. The scientist technique alignment exercise was repeated after the first block of PSGs. Each PSG was thus analysed twice by each scientist, once each with the $\mathrm{AASM}_{1999}$ and the AASM $_{2007-A L T}$ respiratory criteria. The AASM 1999 respiratory scoring criteria was applied in conjunction with R\&K sleep staging and American Sleep Disorders Association arousal scoring (defined as an abrupt shift in electroencephalography frequency, with frequency greater than $16 \mathrm{~Hz}$ but not spindle activity, at least three seconds in duration, and in REM sleep with concurrent electromyography increase) [24], while the AASM $_{2007-A L T}$ respiratory scoring was applied in conjunction with the accompanying $\mathrm{AASM}_{2007}$ rules for sleep staging and arousal scoring.

Change in AHI between the two analysis techniques was the primary outcome of interest. Event-by-event respiratory concordance, change in sleep staging, arousal, and respiratory event related arousal, are presented with further detail online. Inter-rater reliability for AHI was analysed with two-way, random, absolute agreement, intraclass correlation coefficients (ICC) for each rule-set. Data were averaged across the three scorers prior to analyses, to provide mean values for each separate PSG for each rule-set.

\section{Analysis 2}

The inter-rater reliability of the scorers in Analysis 1 was excellent (see Results). As such, a single experienced sleep scientist (above) reviewed each respiratory event within the PSGs previously marked according to the $\mathrm{AASM}_{1999}$ criteria to establish whether it met the $\mathrm{AASM}_{2012}$ respiratory event criteria as previously described [12].
Table 1 Participant demographic and injury information

\begin{tabular}{|c|c|c|}
\hline & $\begin{array}{l}\text { Analysis 1: } \\
\text { acute tetraplegia }\end{array}$ & $\begin{array}{l}\text { Analysis 2: } \\
\text { chronic tetraplegia }\end{array}$ \\
\hline \multicolumn{3}{|c|}{$N(\%)$ or Mean (SD), Min-Max } \\
\hline$N$ & 24 & 78 \\
\hline Sex M / F & $22 / 2$ & $59 / 19$ \\
\hline Age & $\begin{array}{l}39.63(17.47) \\
18.00-69.00\end{array}$ & $\begin{array}{l}43.92(12.31) \\
20.00-70.00\end{array}$ \\
\hline \multicolumn{3}{|l|}{ Injury level } \\
\hline $\mathrm{T} 1$ & - & $3(4 \%)$ \\
\hline $\mathrm{C} 8$ & - & $1(1 \%)$ \\
\hline $\mathrm{C} 7$ & $3(13 \%)$ & $7(9 \%)$ \\
\hline C6 & $2(8 \%)$ & $18(23 \%)$ \\
\hline $\mathrm{C} 5$ & $13(54 \%)$ & $25(32 \%)$ \\
\hline $\mathrm{C} 4$ & $5(21 \%)$ & $20(26 \%)$ \\
\hline $\mathrm{C} 3$ & $1(4 \%)$ & $3(4 \%)$ \\
\hline $\mathrm{C} 2$ & - & - \\
\hline $\mathrm{C} 1$ & - & $1(1 \%)$ \\
\hline \multicolumn{3}{|l|}{$A I S$} \\
\hline A & $10(41 \%)$ & $35(45 \%)$ \\
\hline $\mathrm{B}$ & $5(21 \%)$ & $9(11 \%)$ \\
\hline $\mathrm{C}$ & $4(17 \%)$ & $9(11 \%)$ \\
\hline $\mathrm{D}$ & $5(21 \%)$ & $22(29 \%)$ \\
\hline $\mathrm{E}$ & - & $3(4 \%)$ \\
\hline $\begin{array}{l}\text { Time since } \\
\text { injury }\end{array}$ & $\begin{array}{l}\text { Days: } 59.63(40.51) \text {, } \\
5.00-178.00\end{array}$ & $\begin{array}{l}\text { Years: } 12.21(7.90), \\
1.30-37.96\end{array}$ \\
\hline BMI & 24.35 (3.87), 18.10-33.31 & $\begin{array}{l}24.97(3.96) \\
15.89-37.10\end{array}$ \\
\hline $\mathrm{AHI}^{\wedge}$ & $\begin{array}{l}34.77(27.19), \\
2.30-107.00\end{array}$ & $\begin{array}{l}26.94(23.39) \\
2.40-116.10\end{array}$ \\
\hline
\end{tabular}

AIS American Spinal Injury Association Impairment Scale [24], $B M I$ body mass index, $A H I$ apnoea hypopnoea index

${ }^{\wedge} \mathrm{AHI}$ derived from original clinical diagnostic analysis of the PSG (using $\mathrm{AASM}_{1999}$ criteria) and used to order PSGs by sleep apnoea severity for grouping and random selection within severity terciles

\section{Results}

\section{Analysis 1: comparison of $\mathrm{AHI}_{1999}-\mathrm{AASM}_{2007-\mathrm{ALT}}$}

Participant details are included in Table 1 and event-by-event comparisons between rule-sets are detailed online. Briefly, event-by-event respiratory analyses showed substantial changes to the hypopnoeas scored between rule-sets. Seventy percent of hypopnoeas scored with $\mathrm{AASM}_{1999}$, were scored differently using the AASM $_{2007-A L T}$ criteria (Online Tables 1 and 2). Respiratory event related arousals and respiratory disturbance indices are presented online (Online Table 3 and Fig. 1). The $\mathrm{AASM}_{2007}$ rule-set produced significantly less Stage 2 non-Rapid Eye Movement sleep (N2) and more Rapid Eye Movement (REM or Stage R) sleep than R\&K. Twenty percent of R\&K Stage 2 sleep was classified into 


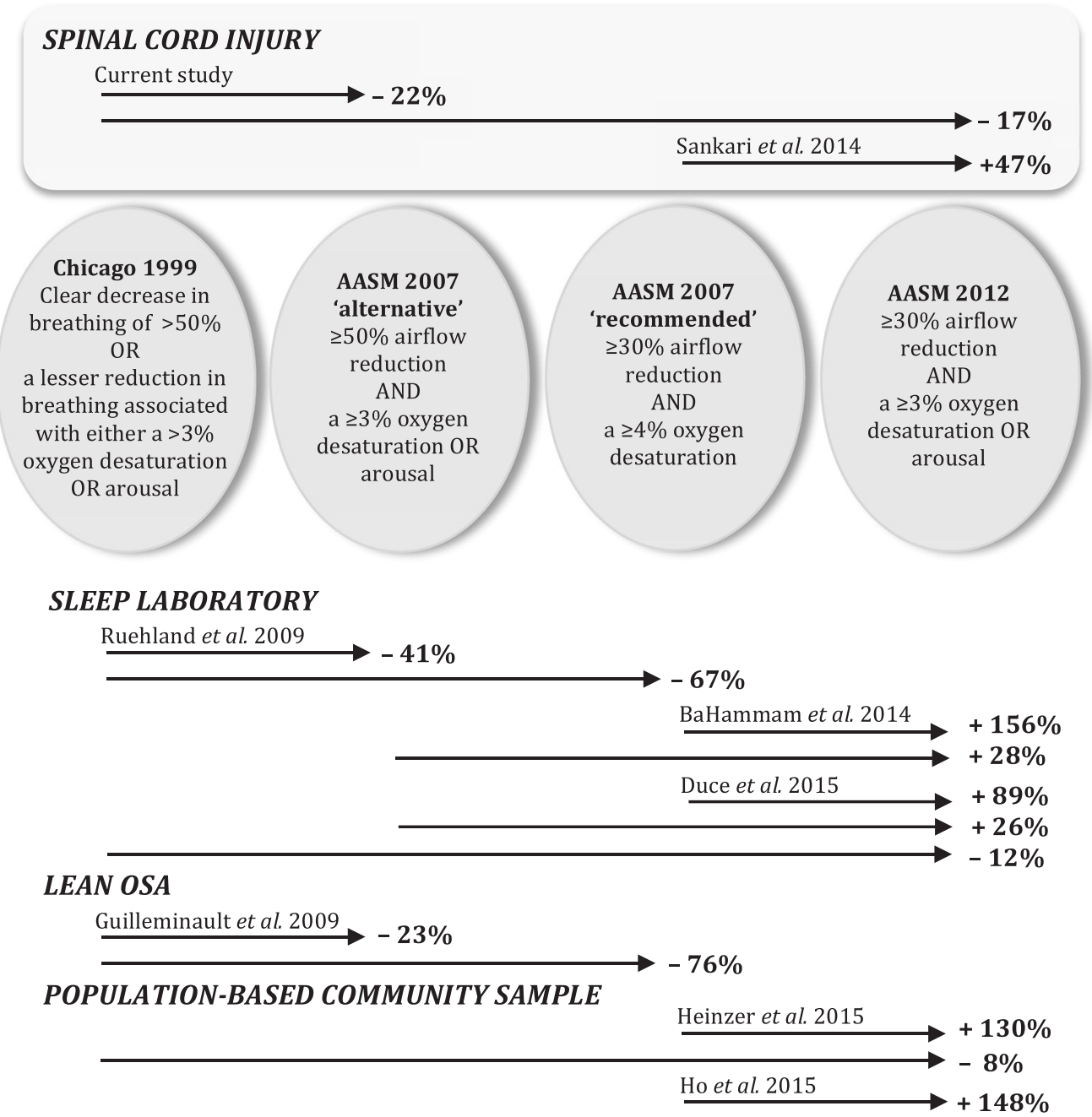

Fig. 1 Illustrated change in American Association for Sleep Medicine (AASM) respiratory event scoring definitions, and the effects on the average apnoea hypopnoea index (AHI) across various samples.

alternative stages using $\mathrm{AASM}_{2007}$, most commonly Stage 1 (N1) and REM (Stage R). Nineteen percent of $\mathrm{AASM}_{2007}$ Stage $R$ was classified differently using $R \& K$, most frequently as Stage 1 and 2 (Online Tables 4 and 5). Overall, event-by-event analyses demonstrated good reliability between scorers and where differences were observed, they were predominantly in the marking of arousals.

Excellent AHI reliability was observed between scientists $\quad\left(\mathrm{AASM}_{1999} \quad \mathrm{ICC}=0.995, \quad 95 \% \mathrm{CI}=0.991-0.998\right.$; $\left.\mathrm{AASM}_{2007-\mathrm{ALT}} \mathrm{ICC}=0.997,95 \% \mathrm{CI}=0.993-0.997\right)$. The $\mathrm{AHI}_{2007-\mathrm{ALT}}$ was significantly lower than the $\mathrm{AHI}_{1999}$ across all SDB severities (Table 2). The mean $\mathrm{AHI}_{2007-\mathrm{ALT}}$ was $78 \%$ of the mean $\mathrm{AHI}_{1999}$, and the proportional effect of the reduction with $\mathrm{AHI}_{2007-\mathrm{ALT}}$ was largest in those with milder disease (Table 2).

The change from $\mathrm{AASM}_{1999}$ to the $\mathrm{AASM}_{2007-\mathrm{ALT}}$ resulted in $17 \%$ of the participants dropping below the SDB diagnostic threshold (AHI of 5), and a quarter
Figure note: Changes in the apnoea hypopnoea index are calculated from overall group mean or median AHI (as provided) for each study and rule set $(2,11-16)$

of the participants moved to a less severe SDB category (Table 3). Table 4 provides equivalent cut-points using AASM $_{2007-A L T}$ criteria for AASM ${ }_{1999}$ AHI values of 5, 15 and 30 , for current and past $[11,12]$ study findings.

\section{Analysis 2: comparison of $\mathrm{AASM}_{1999-\mathrm{AASM}_{2012}}$}

The calculated $\mathrm{AHI}_{2012}$ were on average $83 \%$ of the $\mathrm{AHI}_{1999}$ and significantly lower across all SDB severities (Table 5). Approximately half of the participants previously classified as having mild (AHI $5<15$ ) or moderate (AHI $15<30$ ) SDB were reclassified into a lower severity using the $\mathrm{AASM}_{2012}$ criteria (Table 6); $48 \%$ of those previously classified as 'mild SDB' would no longer meet criteria for having SDB based on the AHI alone. Equivalent AHI cutpoints of $\mathrm{AASM}_{1999}$ severity criteria were calculated at 3 (equivalent to mild), 10 (moderate) and 21 (severe) for the $\mathrm{AASM}_{2012}$ criteria (Table 7). 
Table 2 Change in apnoea hypopnoea index (AHI) and significant differences between the 1999 American Academy of Sleep Medicine (AASM) AHI (AHI $\left.{ }_{1999}\right)$ and the 2007 AASM 'alternative' AHI (AHI $\left.2007-\mathrm{ALT}\right)$ in people with acute tetraplegia. Data are presented as mean (SD) and ranges (minimum to maximum) for each sleep apnoea severity group, and overall

\begin{tabular}{|c|c|c|c|c|c|}
\hline & $N$ & $\mathrm{AHI}_{1999}$ & $\mathrm{AHI}_{2007-\mathrm{ALT}}$ & $\mathrm{AHI}_{1999}-\mathrm{AHI}_{2007-\mathrm{ALT}}$ difference & $\mathrm{AHI}_{2007-\mathrm{ALT}} \%$ of $\mathrm{AHI}_{1999}$ \\
\hline AHI 5-15 & 6 & 9.39 (3.13), 5.00-13.70 & $3.63(1.81), 1.43-6.00$ & $5.76(1.39), 3.57-7.17 * *$ & $38 \%$ \\
\hline AHI $15-30$ & 6 & 21.06 (3.83), 16.43-26.40 & 13.63 (5.69), 8.07-23.9 & 7.43 (3.12), 2.47-11.93* & $65 \%$ \\
\hline $\mathrm{AHI}>30$ & 12 & 61.88 (20.86), 42.30-109.23 & 51.41 (25.91), 16.27-108.4 & $10.47(8.30),-1.10-27.50 *$ & $83 \%$ \\
\hline All & 24 & 38.55 (28.27), 5.00-109.23 & 30.02 (28.62), $1.43-08.4$ & $8.53(6.31),-1.10-27.50 * *$ & $78 \%$ \\
\hline
\end{tabular}

Sleep apnoea severities grouped by $\mathrm{AHI}_{1999}$

$* p<.05$

$* * p<.001$

Table 3 Sleep apnoea severity classification change from 1999 American Academy of Sleep Medicine $\left(\mathrm{AASM}_{1999}\right)$ to 2007 AASM 'alternative' criteria (AASM 2007-ALT ) in people with acute tetraplegia

\begin{tabular}{lllll}
\hline SM $_{1999}$ sleep apnoea severity & & & \\
\hline & & AHI $5<15$ & AHI 15<30 & AHI $\geq 30$ \\
\hline $\begin{array}{l}\text { AASM }_{2007-A L T} \\
\text { sleep apnoea } \\
\text { severity }\end{array}$ & AHI $<5$ & $67 \%$ & $0 \%$ & $0 \%$ \\
& AHI 5<15 & $33 \%$ & $83 \%$ & $0 \%$ \\
& AHI 15< & $0 \%$ & $17 \%$ & $8 \%$ \\
& AHI $\geq 30$ & $0 \%$ & $0 \%$ & $92 \%$ \\
\hline
\end{tabular}

$A H I$ apnoea hypopnoea index

\section{Discussion}

These data demonstrate the effect of different sleep staging and respiratory scoring rules on measures of SDB severity and diagnosis. Sleep disordered breathing is highly prevalent and frequently severe in tetraplegia, but if sleep scoring rules change the indices, with no change in underlying disease, it is difficult for patients, clinicians and policy makers to know what to do. A similar process of examining comparability of measures of injury completeness was undertaken with the American Spinal Injury Association classification standards in 2002 [25]. The current study demonstrates the magnitude of the effect of change in respiratory criteria over time and across multiple rule sets for people with and without SCI. Additionally, we provide diagnostic and severity thresholds for people with SCI, which could guide clinical practice. These 'threshold for disease' changes over time are particularly important in SCI for patients with milder disease where clinically important changes in diagnosis and treatment of disease might occur.

Inconsistencies have arisen in the literature around the prevalence of SDB in people with SCI. For example, the prevalence of SDB in people with acute tetraplegia has been reported at $83 \%$ when the $\mathrm{AASM}_{1999}$ criteria are employed and at $53 \%$ with the $\mathrm{AASM}_{2007}$ criteria [26]. This difference
Table 42007 American Academy of Sleep Medicine (AASM)

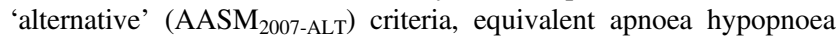
index (AHI) cut-points for $\mathrm{AASM}_{1999}$ sleep apnoea severity classifications, across current and previous study findings

\begin{tabular}{|c|c|c|c|}
\hline & \multicolumn{3}{|c|}{ Existing AASM $_{1999}$ AHI cut-point } \\
\hline & 5 & 15 & 30 \\
\hline \multicolumn{4}{|c|}{ Equivalent cut-points for $\mathrm{AASM}_{2007-\mathrm{ALT}}$} \\
\hline \multicolumn{4}{|l|}{ Current study } \\
\hline AHI cut-point & 2.4 & 8.1 & 16.3 \\
\hline Sensitivity (\%) & 100 & 100 & 100 \\
\hline Specificity $(\%)$ & 100 & 100 & 92 \\
\hline ROC AUC & 1.00 & 1.00 & 0.99 \\
\hline \multicolumn{4}{|c|}{ Ruehland et al. 2009} \\
\hline AHI cut-point & 2.8 & 8.9 & 18.4 \\
\hline Sensitivity (\%) & 92 & 90 & 96 \\
\hline Specificity (\%) & 93 & 91 & 95 \\
\hline ROC AUC & 0.97 & 0.97 & 0.99 \\
\hline \multicolumn{4}{|l|}{ Duce et al. 2015} \\
\hline AHI cut-point & 4.1 & 10.4 & 22.2 \\
\hline Sensitivity $(\%)$ & 97 & 94 & 91 \\
\hline Specificity $(\%)$ & 83 & 89 & 96 \\
\hline ROC AUC & 0.98 & 0.97 & 0.97 \\
\hline
\end{tabular}

Current study participants $(n=24)$ with acute tetraplegia; Ruehland et al. $(n=328)$ [12] and Duce et al. $(n=112)$ [10] consecutive ablebodied sleep laboratory patients

$R O C A U C$ receiver operator curve area under the curve

in prevalence would in large part be attributable to the different criteria used, however this is often not adequately considered in the discussion of such findings. Similarly, longitudinal change in SDB severity for an individual is difficult to interpret from an AHI that may have been scored differently over time.

The $\mathrm{AASM}_{1999}$ criteria were the only criteria to provide cut-off recommendations for diagnosis and severity thresholds of SDB [8]. With changes to criteria, the AASM have advised that thresholds should be adjusted depending on the respiratory event definition being used, however they have not provided revised cut-off estimates [10]. People 
Table 5 Change in apnoea hypopnoea index (AHI) and significant differences between the 1999 American Academy of Sleep Medicine (AASM) AHI ( $\mathrm{AHI}_{1999)}$ and the 2012 AASM AHI ( $\left.\mathrm{AHI}_{2012}\right)$ in people with chronic tetraplegia. Data are presented as mean (SD) and ranges (minimum to maximum) for each sleep apnoea severity group, and overall

\begin{tabular}{llllll}
\hline & $N$ & AHI $_{1999}$ & AHI $_{2012}$ & AHI $_{1999-\mathrm{AHI}_{2012} \text { difference }} \mathrm{AHI}_{2012} \%$ of $\mathrm{AHI}_{1999}$ \\
\hline AHI $<5$ & 11 & $3.81(0.81), 2.40-4.90$ & $2.13(0.98), 0.90-3.80$ & $1.67(0.96), 0.00-3.60 * *$ & $56 \%$ \\
AHI $5<15$ & 21 & $9.73(3.31), 5.40-14.40$ & $5.88(3.11), 1.00-12.00$ & $3.85(1.77), 0.00-7.20^{* *}$ & $60 \%$ \\
AHI $15<30$ & 16 & $19.48(3.57), 15.00-26.80$ & $13.87(4.24), 7.10-19.70$ & $5.61(3.29), 1.10-13.90 * *$ & $71 \%$ \\
AHI $\geq 30$ & 30 & $51.47(19.19), 30.50-116.10$ & $45.88(20.80), 21.20-115.80$ & $5.59(5.13), 0.00-22.70 * *$ & $89 \%$ \\
All & 78 & $26.95(23.39), 2.40-116.10$ & $22.38(23.07), 0.90-115.80$ & $4.57(3.86), 0.00-22.70 * *$ & $83 \%$ \\
\hline
\end{tabular}

Sleep apnoea severities grouped by $\mathrm{AHI}_{1999}$

$* p<.05$

$* * p<.001$

Table 6 Change in sleep apnoea severity classification from 1999 American Academy of Sleep Medicine (AASM) apnoea hypopnoea index (AHI) (AHI 1999$)-2012$ AASM AHI $\left(\mathrm{AHI}_{2012}\right)$ in people with chronic tetraplegia

\begin{tabular}{llllll}
\hline & \multicolumn{4}{l}{ AASM $_{1999}$ sleep apnoea severity } \\
\cline { 3 - 5 } & & AHI $<5$ & AHI $5<15$ & AHI $15<30$ & AHI $\geq 30$ \\
\hline $\begin{array}{l}\text { AASM }_{2012} \\
\text { sleep apnoea severity }\end{array}$ & AHI $<5$ & $100 \%$ & $48 \%$ & $0 \%$ & $0 \%$ \\
& AHI 5 $<15$ & $0 \%$ & $52 \%$ & $50 \%$ & $0 \%$ \\
& AHI 15 $<30$ & $0 \%$ & $0 \%$ & $50 \%$ & $20 \%$ \\
& AHI $\geq 30$ & $0 \%$ & $0 \%$ & $0 \%$ & $80 \%$ \\
\hline
\end{tabular}

Table 72012 American Academy of Sleep Medicine (AASM) criteria $\left(\mathrm{AASM}_{2012}\right.$ ) equivalent apnoea hypopnoea index (AHI) cut-points for $\mathrm{AASM}_{1999}$ sleep apnoea severity classifications, for current and previous study findings

\begin{tabular}{|c|c|c|c|}
\hline & \multicolumn{3}{|c|}{ Existing AASM $_{1999}$ AHI cut-point } \\
\hline & 5 & 15 & 30 \\
\hline \multicolumn{4}{|c|}{ Equivalent cut-points for $\mathrm{AASM}_{2012}$} \\
\hline \multicolumn{4}{|l|}{ Current study } \\
\hline AHI cut-point & 3.2 & 10.0 & 21.2 \\
\hline Sensitivity (\%) & 94 & 94 & 100 \\
\hline Specificity $(\%)$ & 91 & 88 & 100 \\
\hline ROC AUC & 0.97 & 0.98 & 1.00 \\
\hline \multicolumn{4}{|l|}{ Duce et al. 2015} \\
\hline AHI cut-point & 4.5 & 12.3 & 28.3 \\
\hline Sensitivity $(\%)$ & 99 & 97 & 93 \\
\hline Specificity $(\%)$ & 100 & 99 & 97 \\
\hline ROC AUC & 1.00 & 1.00 & 0.98 \\
\hline
\end{tabular}

Current study participants $(n=78)$ with chronic tetraplegia; Duce et al. $(n=112)$ [10] consecutive able-bodied sleep laboratory patients

ROC AUC receiver operator curve area under the curve

with SCI are a unique population group in their SDB pathophysiology, incidence and severity [27-29]. Figure 1 illustrates respiratory event definition changes over time and the resultant impact on AHI in people with SCI [2], in sleep laboratory samples [11-13], lean OSA [14], and the general able-bodied population $[15,16]$. Overall, the change from $\mathrm{AASM}_{1999}$ to $\mathrm{AASM}_{2007}$ resulted in the largest changes in AHI, while the introduction of the $\mathrm{AASM}_{2012}$ criteria has returned the $\mathrm{AHI}$ closer to the original $\mathrm{AHI}_{1999}$. The $\mathrm{AASM}_{2012}$ hypopnoea definition intermediates the $\mathrm{AASM}_{2007-\mathrm{ALT}}$ and previous $\mathrm{AASM}_{1999}$ criteria, and importantly includes both arousal and desaturation which each have detrimental effects and individually impact treatment outcome [14]. Each AASM revision simply calls the apnoea hypopnoea index the "AHI", with no designation as to which rule-set was applied. It is likely that future AASM revisions will alter the landscape again and as such, cut-off revisions may be needed again.

Sankari et al. [2] investigated the change in AHI from $\mathrm{AASM}_{2007-R E C}$ to $\mathrm{AASM}_{2012}$ rule-sets in 26 participants with thoracic and cervical SCI. The people with SCI investigated by Sankari et al. [2] had more severe SDB overall than other able-bodied samples from sleep laboratory populations, and the overall percentage change in AHI was less (Fig. 1). The current study examined the PSGs of 102 people with acute and chronic tetraplegia. Similarly, with more severe SDB, the change from $\mathrm{AASM}_{1999}$ to $\mathrm{AASM}_{2007-\mathrm{ALT}}$ in people with acute SCI was less than that of sleep laboratory samples, and aligned more closely with the lean OSA patients who were of similar BMI [14].

Reclassification of SDB according to new respiratory criteria $\left(\mathrm{AASM}_{2012}\right.$ and $\mathrm{AASM}_{2007-\mathrm{ALT}}$ ), with use of the only pre-existing thresholds (set out by the $\mathrm{AASM}_{1999}$ ruleset) for diagnosis and severity [8] resulted in a nondiagnosis of SDB for 48-67\% of people previously classified as having mild SDB according to the $\mathrm{AASM}_{1999}$ 
respiratory criteria, highlighting the need for adjusted thresholds. The variability in degree of change between populations highlighted in Fig. 1 also demonstrates the utility of population-specific thresholds. For people with SCI, pre-existing AHI thresholds of 5, 15 and 30, are revised to 2.4, 8.1 and 16.3 for $\mathrm{AASM}_{2007-\mathrm{ALT}}$ and 3.2, 10.0 and 21.2 for $\mathrm{AASM}_{2012}$. These are important not only for appropriate clinical practice, but interpretation of research and prevalence data published over time.

A limitation of the current study was that PSGs were scored using nasal pressure only, and not with the recommended standard for apnoea detection, both nasal pressure and thermistor. However, Thornton et al. [30] found that AHI from nasal pressure alone was 3\% higher than with nasal pressure and thermistor, and concluded that analysis without a thermistor signal would have only a modest impact. Reliability between scorers in the current study was consistent with other research of similar methodology investigating inter-rater reliability in sleep analyses [31, 32], and both current and previous research have demonstrated that arousal scoring is less reliable than sleep staging and respiratory scoring [32, 33]. The $\mathrm{AASM}_{2007-\mathrm{ALT}}$ and $\mathrm{AASM}_{2012}$ have put greater importance on the arousal compared to $\mathrm{AASM}_{1999}$ which did not require an arousal (or desaturation) to mark a hypopnoea if the decrease in breathing was greater than $50 \%$. The marking of arousals merits significant attention in training and concordance measurement for sleep staging and respiratory scoring. Differences in PSG recording sensors and technologies also contribute to differences in severity estimates in the literature. For example, a metaanalysis has shown that home sleep studies can underestimate sleep apnoea severity [34], however this metaanalysis included many 'home sleep studies' that were not Type 2 'full PSG' (and therefore did not measure the same signals as Type 1 in-laboratory PSG) and only estimated sleep and respiration rather than measure them. In the current study this confounder was able to be avoided by standard use of a Type 2 PSG device (measuring the same signals as an in-laboratory PSG) and as such our results reflect comparisons in AASM rules only. However, we cannot discount the possibility of differential results due to the ambulatory nature of the sleep studies and so this remains a possible limitation of the current study.

Understanding change in AHI is important with every change of rules, including in clinically distinct populations such as SCI. Regardless of the underlying factors contributing to differences between the population groups investigated to date, the variable degree of change in AHI across population groups highlights the need for population specific prevalence data to inform index interpretation. Clinicians treating patients with SCI must ensure current and accurate interpretation of $\mathrm{AHI}$ indices and the shifting thresholds for diagnosis and severity. Additionally, interpreting research and prevalence data conducted over different time periods, with different analysis (and data collection) rule-sets, requires knowledge of the relationship between each rule-set over time. At an individual patient care level, understanding that the AHI may have changed in a person over time because the rules changed, rather than because the person changed, is important. It is recommended that future updates to respiratory event definitions provide distinct nomenclature for each iteration of the 'AHI' and be accompanied by research which quantifies change in AHI from the outset, providing immediate knowledge of required adjustment of interpretation. There may also be a role for the development of SCI-specific guidance documentation.

\section{Data archiving}

Deidentified group data, as per informed consent, are all made available within the paper and supplementary material.

Acknowledgements This project was proudly supported by the Traffic Accident Commission (Program grant) and the National Health and Medical Research Council (PhD stipend 616605).

Author contributions RS was involved in the literature review, study design, data collection, analysis of data, manuscript preparation and review of the manuscript. MG was involved in study design, data collection, analysis of data, manuscript preparation and review of the manuscript. JS and DJB were involved in study design, analysis of data, manuscript preparation and review of the manuscript. WR, JT, $\mathrm{PR}$ and BS were involved in study design, analysis of data and review of the manuscript. BD was involved in data collection and review of the manuscript.

\section{Compliance with ethical standards}

Conflict of interest The authors declare that they have no conflict of interest.

Ethical approval The authors certify that all applicable institutional and governmental regulations concerning the ethical use of human volunteers were followed during the course of this research.

\section{References}

1. Berlowitz DJ, Spong J, Gordon I, Howard ME, Brown DJ. Relationships between objective sleep indices and symptoms in a community sample of people with tetraplegia. Arch Phys Med Rehabil. 2012;93:1246-52.

2. Sankari A, Bascom AT, Oomman S, Badr MS. Sleep disordered breathing in chronic spinal cord injury. J Clin Sleep Med. 2014;10:65-72.

3. Spong J, Graco M, Brown DJ, Schembri R, Berlowitz DJ. Subjective sleep disturbances and quality of life in chronic tetraplegia. Spinal Cord. 2015;53:636.

4. Sajkov D, Marshall R, Walker P, Mykytyn I, McEvoy RD, Wale $\mathrm{J}$, et al. Sleep apnoea related hypoxia is associated with 
cognitive disturbances in patients with tetraplegia. Spinal Cord. 1998;36:231-39.

5. Schembri R, Spong J, Graco M, Berlowitz D. Neuropsychological function in patients with acute tetraplegia and sleep disordered breathing. Sleep. 2017;40:1-6.

6. Chiodo AE, Sitrin RG, Bauman KA. Sleep disordered breathing in spinal cord injury: a systematic review. J Spinal Cord Med. 2017;39:374-82.

7. Rechtschaffen A, Kales A. A manual of standardized terminology, technique and scoring system for sleep stages of human subjects. Los Angeles: Brain Information Service, Brain Research Institute, UCLA; 1968.

8. American Academy of Sleep Medicine Task Force. Sleep-related breathing disorders in adults: recommendations for syndrome definition and measurement techniques in clinical research. Sleep. 1999;22:667-89.

9. Iber C, Ancoli-Israel S, Chesson A, Quan S. The AASM manual for the scoring of sleep and associated events: rules, terminology and technical specifications. 1st ed. Westchester, IL: American Academy of Sleep Medicine; 2007.

10. Berry RB, Budhiraja R, Gottlieb DJ, Gozal D, Iber C, Kapur VK, et al. Rules for scoring respiratory events in sleep: update of the 2007 AASM Manual for the Scoring of Sleep and Associated Events. Deliberations of the Sleep Apnea Definitions Task Force of the American Academy of Sleep Medicine. J Clin Sleep Med. 2012;8:597-619.

11. Duce B, Milosavljevic J, Hukins C. The 2012 AASM respiratory event criteria increase the incidence of hypopneas in an Adult Sleep Center Population. J Clin Sleep Med. 2015;11:1425-31.

12. Ruehland WR, Rochford PD, O'Donoghue FJ, Pierce RJ, Singh P, Thornton AT. The new AASM criteria for scoring hypopneas: impact on the apnea hypopnea index. Sleep. 2009;32:150-7.

13. BaHammam AS, Obeidat A, Barataman K, Bahammam SA, Olaish AH, Sharif MM. A comparison between the AASM 2012 and 2007 definitions for detecting hypopnea. Sleep Breath. 2014;18:767-73. (4)

14. Guilleminault C, Hagen CC, Huynh NT. Comparison of hypopnea definitions in lean patients with known obstructive sleep apnea hypopnea syndrome (OSAHS). Sleep Breath. 2009;13:341-7.

15. Ho V, Crainiceanu CM, Punjabi NM, Redline S, Gottlieb DJ. Calibration model for apnea-hypopnea indices: impact of alternative criteria for hypopneas. Sleep. 2015;38:1887-92.

16. Heinzer R, Vat S, Marques-Vidal P, Marti-Soler H, Andries D, Tobback N, et al. Prevalence of sleep-disordered breathing in the general population: the HypnoLaus study. Lancet Respir Med. 2015;3:310-8.

17. Vat S, Haba-Rubio J, Tafti M, Tobback N, Andries D, Heinzer R. Scoring criteria for portable monitor recordings: a comparison of four hypopnoea definitions in a population-based cohort. Thorax. 2015.

18. Nieto FJ, Young TB, Lind BK, Shahar E, Samet JM, Redline S, et al. Association of sleep-disordered breathing, sleep apnea, and hypertension in a large community-based study. Sleep Heart Health Study. JAMA. 2000;283:1829-36.

19. Campos-Rodriguez F, Martínez-García MA, Reyes-Nuñez N, Selma-Ferrer MJ, Punjabi NM, Farre R. Impact of different hypopnea definitions on obstructive sleep apnea severity and cardiovascular mortality risk in women and elderly individuals. Sleep Med. 2016;27:54-8.

20. Ward NR, Roldao V, Cowie MR, Rosen SD, McDonagh TA, Simonds AK, et al. The effect of respiratory scoring on the diagnosis and classification of sleep disordered breathing in chronic heart failure. Sleep. 2013;36:1341-8.

21. Australasian Sleep Technologists Association (ASTA), Australasian Sleep Association (ASA). ASTA/ASA commentary on AASM manual for the scoring of sleep and associated events. 2010; Version1.7.

22. Berlowitz DJ, Ayas N, Barnes M, Brown DJ, Cistulli PA, Geraghty $\mathrm{T}$, et al. Auto-titrating continuous positive airway pressure treatment for obstructive sleep apnoea after acute quadriplegia (COSAQ): study protocol for a randomized controlled trial. Trials. 2013;14:1-10.

23. Graco M, Schembri R, Cross S, Thiyagarajan C, Shafazand S, Ayas N, et al. Diagnostic accuracy of a two-stage model for detecting obstructive sleep apnoea in chronic tetraplegia. Thorax. 2018.

24. Bonnett M, Carley D, Carskadon M. EEG arousal: scoring rules and examples: a preliminary report from the sleep disorders atlas task force of the American Sleep Disorders Association. Sleep. 1992;15:173-84.

25. Kirshblum SC, Memmo P, Kim N, Campagnolo D, Millis S. Comparison of the revised 2000 American Spinal Injury Association classification standards with the 1996 guidelines. Am J Phys Med Rehabil. 2002;81:502-5. (7)

26. Proserpio P, Lanza A, Sambusida K, Fratticci L, Frigerio P, Sommariva $\mathrm{M}$, et al. Sleep apnea and periodic leg movements in the first year after spinal cord injury. Sleep Med. 2015;16:59-66.

27. Fuller D. How does spinal cord injury lead to obstructive sleep apnoea? J Physiol. 2018.

28. Gainche L, Berlowitz DJ, LeGuen M, Ruehland WR, O'Donoghue FJ, Trinder J, et al. Nasal resistance is elevated in people with tetraplegia and is reduced by topical sympathomimetic administration. J Clin Sleep Med. 2016;12:1487-92.

29. Wijesuriya NS, Gainche L, Jordan AS, Berlowitz DJ, LeGuen M, Rochford PD, et al. Genioglossus reflex responses to negative upper airway pressure are altered in people with tetraplegia and obstructive sleep apnoea. J Physiol. 2018.

30. Thornton AT, Singh P, Ruehland WR, Rochford PD. AASM criteria for scoring respiratory events: Interaction between apnea sensor and hypopnea definition. Sleep. 2012;35:425-32.

31. Danker-Hopfe H, Anderer P, Zeitlhofer J, Boeck M, Dorn H, Gruber $\mathrm{G}$, et al. Interrater reliability for sleep scoring according to the Rechtschaffen \& Kales and the new AASM standard. J Sleep Res. 2009;18:74-84.

32. Ruehland WR, O'Donoghue FJ, Pierce RJ, Thornton AT, Singh P, Copland JM, et al. The 2007 AASM recommendations for EEG electrode placement in polysomnography: impact on sleep and cortical arousal scoring. Sleep. 2011;34:73-81. (1)

33. Whitney CW, Gottlieb DJ, Redline S, Norman RG, Dodge RR, Shahar E, et al. Reliability of scoring respiratory disturbance indices and sleep staging. Sleep. 1998;21:749-57.

34. Ghegan MD, Angelos PC, Stonebraker AC, Gillespie MB. Laboratory versus portable sleep studies: a meta-analysis. Laryngoscope. 2006;116:859-64. 